\title{
Kai tahu taoka. Treasures from the Otago Museum de Otago Museum
}

\section{Gilles Bounoure}

\section{(2) OpenEdition \\ 1 Journals}

\section{Édition électronique}

URL : http://journals.openedition.org/jso/2222

DOI : $10.4000 /$ jso.2222

ISSN : $1760-7256$

\section{Éditeur}

Société des océanistes

\section{Édition imprimée}

Date de publication : 15 décembre 2008

Pagination : 353

ISBN : 978-2-85430-012-3

ISSN : 0300-953x

\section{Référence électronique}

Gilles Bounoure, «Kai tahu taoka. Treasures from the Otago Museum de Otago Museum », Journal de la Société des Océanistes [En ligne], 126-127 | Année 2008, mis en ligne le 15 décembre 2008, consulté le 25 septembre 2020. URL : http://journals.openedition.org/jso/2222 ; DOI : https://doi.org/10.4000/jso. 2222

Ce document a été généré automatiquement le 25 septembre 2020.

(c) Tous droits réservés 


\title{
Kai tahu taoka. Treasures from the Otago Museum de Otago Museum
}

\author{
Gilles Bounoure
}

\section{RÉFÉRENCE}

Otago Museum, Kai tahu taoka. Treasures from the Otago Museum, Auckland-Dunedin, Reed Books-Otago Museum, 200 p., environ 180 ill. couleur pleine page, cartes.

1 Ce livre principalement constitué d'illustrations entend rendre hommage au génie artistique du groupement tribal maori Kai Tahu de l'île du Sud, Te Waipounamu, à travers des objets regroupés selon les matériaux mis en œuvre, successivement bois (rakau), coquillage ( $a k a)$, fibre (muka), os (iwi), pierre (pahatu), néphrite (pounamu). Les éditeurs prétendent seulement livrer des arts anciens de l'île du Sud "a small glimpse ", " to think of the creativity that went into their production, and think of the legacy that has been left for us all today». Intention d'autant plus louable que la littérature et l'histoire des arts maori ont jusqu'à présent largement privilégié l'île du Nord, et même parfois dénié à l'île du Sud toute capacité d'invention stylistique, au moins durant la période classique.

2 Avec une grande majorité d'excellentes photos, souvent en gros plan, le livre est superbe, mais souffre d'un défaut patent : les légendes ne comportent ni dimensions ni détails de collecte et contraignent les lecteurs à recourir à des publications plus savantes. Par exemple, pour le premier objet reproduit page 14 et seulement légendé page 196 "D71.233 Carved wooden adze haft, Taieri Mouth », il faut se reporter au recueil d'articles d'Henry D. Skinner (Comparatively Speaking, Studies in Pacific Material Culture 1921-1972, Dunedin, University of Otago Press, 1974: 150), dont cet objet «tokipoutangata helve » forme la couverture et le frontispice, pour disposer de sa description critique. Les dimensions et une description un peu détaillée du « rei puta " reproduit page 99 sont à chercher dans Sydney Moko Mead et al. (Te Maori, Maori Art from New Zealand Collections, New York, Abrams, $\left.1984: 229, \mathrm{n}^{\circ} 162\right)$, et ainsi du reste. 
3 Ce livre restera pour la qualité de ses reproductions photographiques, mais peut-être aussi comme exemple achevé d' "esthétisation " des objets « ethnographiques » dont Sally Price (Arts primitifs : Regards civilisés, Paris, École nationale supérieure des BeauxArts, 1995 : 137, déjà cité dans cette rubrique) a décrit le fonctionnement. C'est par l'extrême laconisme des cartels d'exposition, ou des légendes d'illustration, dont l'effet, sinon l'intention, est de le «décontextualiser», que l'objet "sauvage» est insensiblement élevé au rang de ces "œuvres d'art civilisé » susceptibles de "plaire universellement et sans concept ", aux termes de l'esthétique kantienne. Cette pratique occidentale, contre laquelle s'insurgeait S. Price voilà une décennie, et qu'on observe toujours dans les plus récentes entreprises - américaines, européennes et surtout françaises - de "réhabilitation des arts premiers » (et de "marchandisation » aussi, pour être franc), il n'est pas très étonnant que cet ouvrage d'hommage aux Kai Tahu et à leurs arts l'ait adoptée pour suivre la mode ou par désir d'une " communication » plus efficace, mais on peut douter qu'une telle "décontextualisation » soit réellement à même de faire valoir, dans ce qu'il a d'intrinsèque et d'inimitable, le génie artistique ou autre des Maori présents ou passés, de l'île du Sud ou d'ailleurs. 